\title{
Polycystic ovarian syndrome among adolescent and young women: a hospital based observational study in a tertiary care teaching Hospital
}

\author{
Arpita Jain, Swati Garg*, Urvashi Sharma
}

Department of Obstetrics and Gynecology, Mahatma Gandhi Medical College and Hospital, Jaipur, Rajasthan, India

Received: 20 December 2019

Revised: 24 January 2020

Accepted: 29 January 2020

\section{*Correspondence:}

Dr. Swati Garg,

E-mail: drswatigarg@mgumst.org

Copyright: () the author(s), publisher and licensee Medip Academy. This is an open-access article distributed under the terms of the Creative Commons Attribution Non-Commercial License, which permits unrestricted non-commercial use, distribution, and reproduction in any medium, provided the original work is properly cited.

\begin{abstract}
Background: Polycystic ovarian syndrome (PCOS) is one of the most common endocrine disorder among women of fertile age. The incidence of PCOS as claimed by various observer ranges from $2.2 \%$ to as high as $26 \%$. India is considered as an emerging epidemic area for PCOS and limited studies are done. Hence aim of this study is to find the prevalence of PCOS and determine the associated determining factors in adolescent girls.

Methods: All the girls aged 15-24 years were approached and after undergoing detailed history, examination and investigations were further diagnosed as PCOS. The study subjects were then classified into two group: the PCOS and non-PCOS group and compared to determine significant differences as per the Rotterdam criteria.

Results: The prevalence of PCOS was $7.5 \%, 18.68 \%$ and $11.18 \%$ as per NIH, Rotterdam and AES criteria respectively. BMI more than 30, waist circumference $>80 \mathrm{~cm}$, hyperandrogenic manifestations, menstrual irregularity (oligomenorrhea) and family history of PCOS and DM showed statistically significant association with PCOS. Serum LH, LH/FSH ratio, S. Testosterones, serum insulin and HOMA-IR had significant association with PCOS. No significant association of Fasting blood sugar levels and deranged lipid profile was found with PCOS.

Conclusions: PCOS is an emerging disorder during adolescents and hence awareness creation, early screening in order to inculcate early life style modifications and prevent metabolic and reproductive complications of this disease.
\end{abstract}

Keywords: HOMA-IR, Polycystic ovarian syndrome, Rotterdam, Serum insulin

\section{INTRODUCTION}

Polycystic ovarian syndrome (PCOS) is one of the most frequently encountered hormonal disorder with broad spectrum of clinical manifestations that can present at puberty, during reproductive age or even after menopause. It is probably the most significant public health issue in women, accounting for the majority of cases of hirsutism, menstrual disturbance, and anovulatory infertility.

The incidence of PCOS as claimed by various observer ranges from $2.2 \%$ to as high as $26 \%$, which can be possibly due to different sets of definition evolved through the time. ${ }^{1-4}$ India is considered as an emerging epidemic area for PCOS and reflects the grim situation for the society due to higher incidence but no education regarding the presentation and disease process.

PCOS is a combination of hyperandrogenism (clinical or biochemical), chronic anovulation and polycystic ovaries and is frequently associated with insulin resistance and obesity. ${ }^{5}$ There is also increased risk of infertility, abnormal uterine bleeding, obesity, endometrial cancer, type 2 DM, dyslipidaemia, hypertension and other cardiovascular disease. ${ }^{6,7}$ 
The cause is not clearly known, however multiple factors such as hereditary and nonhereditary; intrauterine and extra uterine; environmental factors; disparity in insulin resistance; modification in steroidogenesis may influence this syndrome.

As this syndrome constitutes variable diverse combination of symptoms. ${ }^{2}$ The patients therefore would have to consult a gynaecologist for menstrual irregularity and infertility, physician for obesity and associated metabolic disorder, dietician for nutritional counselling, dermatologist for hair and skin ailments like acne and hirsutism, endocrinologist for diabetes and psychiatrist for depression as a result of body image disturbances. Each time they get treated for isolated morbidities, which further delays the diagnosis of this multidimensional syndrome. This also accounts for significant health care costs distress and has been found to impact the quality of life of patients.

Therefore, it is important to make an early diagnosis in order to prevent early and late sequel of this syndrome. Studies have shown that the cost of diagnostic evaluation accounts only for a relatively lesser part of the total costs of managing PCOS. Therefore, there should be more widespread and liberal screening as a cost-effective strategy, benefiting earlier diagnosis and intervention and possibly the amelioration and prevention of serious longterm sequel. ${ }^{8}$

PCOS diagnosis has been a topic of debate and many consensuses/definitions have evolved over time (Table 1).

Table 1: PCOS diagnostic criteria.

\begin{tabular}{|c|c|c|}
\hline National institute of health $1990^{9}$ & Rotterdam $2003^{10}$ & Androgen Excess -PCOS society $2006^{11}$ \\
\hline If both the criteria are met & $\begin{array}{l}\text { If two of three criteria } \\
\text { are met }\end{array}$ & $\begin{array}{l}\text { If both the criteria are met (after excluding } \\
\text { other androgen excess or related disorders) }\end{array}$ \\
\hline $\begin{array}{l}\text { - Chronic anovulation } \\
\text { Clinical and/or biochemical signs } \\
\text { of hyper-androgenism (with } \\
\text { exclusion of other aetiologies e.g. } \\
\text { congenital adrenal hyperplasia) }\end{array}$ & 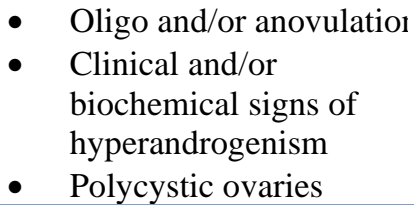 & $\begin{array}{l}\text { - Clinical and/or biochemical signs of } \\
\text { hyperandrogenism } \\
\text { Ovarian dysfunction (Oligo-anovulation } \\
\text { and/or polycystic ovarian morphology) }\end{array}$ \\
\hline
\end{tabular}

Since PCOS tends to present as a spectrum of diseases, the Rotterdam criteria divided the disease into 4 phenotypes arranged in a sequence of decreasing severity. ${ }^{10}$

- Phenotype 1 (Classic PCOS): Hyperandrogenism, Oligo/amenorrhea, polycystic ovaries in USG

- Phenotype 2 (Classic non-polycystic ovaries PCOSthe essential NIH criteria): Hyperandrogenism and oligo/amenorrhea

- $\quad$ Phenotype 3 non-classic ovulatory PCOS (ovulatory PCOS): Hyperandrogenism and polycystic ovaries in USG

- Phenotype 4 (non-classic or non-hyperandrogenic PCOS): Oligo/ amenorrhea and polycystic ovaries in USG.

Despite the presence of several definitions, PCOS is still a diagnosis of exclusion of the other hyperandrogenic cause. With this background, a hospital-based observational study was done in MGMCH, Jaipur, Raj, India to screen adolescents and young girls aged 15-24 years for PCOS and evaluate the prevalence and assess the determinants related to the presence of PCOS.

\section{METHODS}

The present study was a hospital based Observational Study conducted in a tertiary care centre at Mahatma
Gandhi Medical College and Hospital, Jaipur from December 2017 to May 2019.

A sample size of 960 was calculated after considering prevalence of PCOS to be $10.7 \%$ as per Androgen Excess Society and taking the absolute error as $2 \% .^{1}$

With the aim to achieve the sample size of 1000, all the adolescent girls (age group 15-19 years) and Young women (age group 20-24 years) presenting in MGMCH gynaecology and medicine OPD (including allied branched like dermatology and endocrinology), were informed about the aims and objectives of the study, counselled and educated regarding PCOS, its presentation and disease process.

The girls who were willing to participate in the study were enrolled and subjected to the study after obtaining ethical clearance from IEC.

Written and informed consent was obtained from all the patients, for minor girl's consent was taken from parents or guardians.

Among all the study subjects that were approached and explained about the study, only 884 volunteered got enrolled underwent clinical examination and completed USG. However, only 760 of them completed all the biochemical and hormonal tests. 
A structured questionnaire was given to all the participants and detailed history including presenting complaints, menstrual pattern, personal, past, family, obstetric and treatment history was taken and was followed by complete physical examination. Subjects were screened for signs of hyperandrogenism (hirsutism and acne) and insulin resistance (acanthosis nigricans) Ultrasonography to see PCO followed by a set blood investigation on day 3- day 7 of menses (TSH, prolactin, LH, FSH, Testosterone, FBS, Fasting Insulin, HOMA-IR and Lipid Profile) were performed for each subject.

The subjects were then diagnosed as PCOS as per NIH, Rotterdam and Androgen excess society diagnostic criteria. They were further classified into two group based on the diagnosis; the PCOS group as per Rotterdam criteria and non-PCOS group to determine significant differences as per the Rotterdam criteria.

\section{Inclusion criteria}

- $\quad$ Adolescents (15-19 years) and Young women (20-24 years) presenting in OPD of MGMCH

- Girls who gave their consent for the study.

\section{Exclusion criteria}

- Girls below 15 and women above 24 years old

- Girls who have attained menarche less than 2 years back

- Girls who did not give their consent for the study

- Pregnancy

- Thyroid disorder

- Hyperprolactinemia

- Other androgen excess disorder like androgen secreting neoplasia, Cushing's disease and congenital adrenal hyperplasia.

\section{Statistical analysis}

The data was coded and entered into Microsoft Excel spread sheet. Mean, SD of all and parameters were summarized in form of Mean \pm SD. Analysis was done using SPSS version 20 (IBM SPSS statistics Inc., Chicago, Illinois, USA) windows software program. The quantitative data comparison between cases and control of all clinical parameters was done by the unpaired t test Chi square test was used for comparing between the two groups. Level of significance for all statistical analysis was kept at $95 \%$ that is $\mathrm{p} \leq 0.05$.

\section{RESULTS}

The prevalence of PCOS according to different diagnostic criteria which was found to be $7.5 \%, 18.68 \%$ and $11.18 \%$ as per NIH, Rotterdam and androgen excess criteria respectively (Table 2 ).
The most prevalent phenotype was phenotype D (nonhyperandrogenic) and least prevalent was phenotype B in which $11.97 \%$ subjects belonged (Table 3).

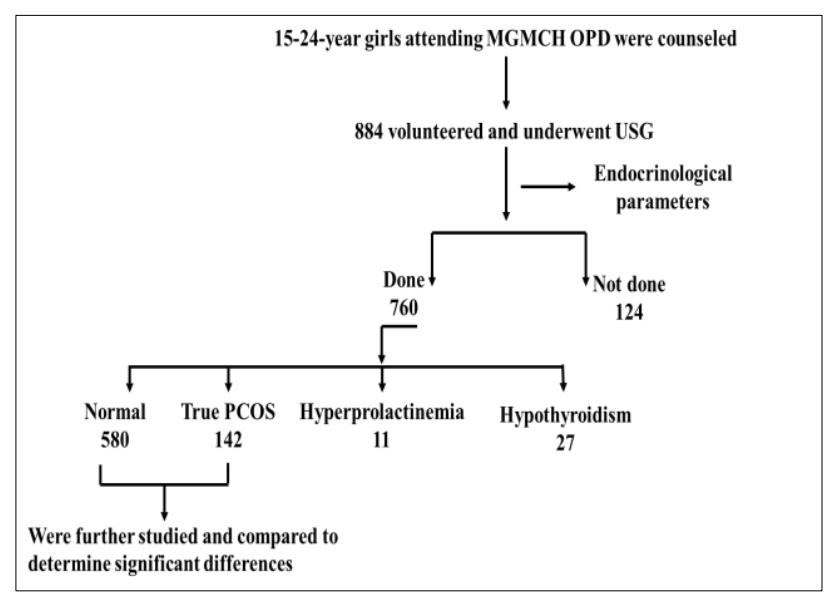

Figure 1: Study population.

Table 2: Prevalence of PCOS.

\begin{tabular}{|lll|}
\hline $\begin{array}{l}\text { PCOS diagnostic } \\
\text { criteria }\end{array}$ & $\begin{array}{l}\text { Number of } \\
\text { subjects }\end{array}$ & $\%$ \\
\hline NIH & 57 & $7.5 \%$ \\
\hline Rotterdam criteria & 142 & $18.68 \%$ \\
\hline Androgen excess criteria & 85 & $11.18 \%$ \\
\hline
\end{tabular}

Table 3: Distribution of PCOS cases according to phenotype.

\begin{tabular}{|c|c|c|}
\hline Phenotype & Number of subjects & $\%$ \\
\hline $\mathrm{A}(\mathrm{O}+\mathrm{H}+\mathrm{P})$ & 40 & 28.17 \\
\hline $\mathrm{B}(\mathrm{O}+\mathrm{H})$ & 17 & 11.97 \\
\hline $\mathrm{C}(\mathrm{H}+\mathrm{P})$ & 28 & 19.72 \\
\hline $\mathrm{D}(\mathrm{O}+\mathrm{P})$ & 57 & 40.14 \\
\hline Total & 142 & 100 \\
\hline
\end{tabular}

Table 4 shows

- Oligomenorrhea was main complain in PCOS girls was found to be statistically significant $(p=0.001)$

- Significantly high number of PCOS girls was having hirsutism, infertility and acanthosis when compared to non PCOS girls

- The prevalence of acne was higher in PCOS girls but occurrence of acne was not statistically significant ( $p$ $=0.11)$ in PCOS girls when compared with non PCOS group.

\section{The following Table 5 shows}

- Percentage of PCOS girls having family history of hypertension (17.6\%), diabetes (19.7\%) and PCOS $(12 \%)$ was higher when compared with non PCOS girls having $17.2 \%, 12.2 \%, 6.4 \%$ respectively 
- Family history of diabetes and PCOS was statistically significant when compared in two groups $(\mathrm{p}=0.02,0.01)$
- Family history of hypertension was not statistically much more different in PCOS and non PCOS girls ( $\mathrm{p}$ $=0.9$ ).

Table 4: Distribution according to the clinical presentation.

\begin{tabular}{|c|c|c|c|c|}
\hline $\begin{array}{l}\text { Clinical } \\
\text { presentation }\end{array}$ & $\begin{array}{l}\text { PCOS }(n=142) \\
\text { No. of subject }(\%)\end{array}$ & $\begin{array}{l}\text { Non PCOS }(\mathbf{n}=\mathbf{5 8 0}) \\
\text { No. of subject }(\%)\end{array}$ & $\begin{array}{l}\text { Total }(\mathrm{n}=\mathbf{7 2 2}) \\
\text { No. of subject }(\%)\end{array}$ & p value \\
\hline \multicolumn{4}{|c|}{ Menstrual irregularities } & \multirow{3}{*}{0.001} \\
\hline Oligo & $114(80.3 \%)$ & $81(14 \%)$ & $195(27 \%)$ & \\
\hline RNF & $28(19.7 \%)$ & $499(86 \%)$ & $527(73 \%)$ & \\
\hline \multicolumn{4}{|l|}{ Hirsutism } & \multirow{3}{*}{0.001} \\
\hline Present & $85(58.9 \%)$ & $94(16.2 \%)$ & $187(25.9 \%)$ & \\
\hline Not present & $57(40.1 \%)$ & $486(83.8 \%)$ & $535(74.1 \%)$ & \\
\hline \multicolumn{4}{|l|}{ Acne } & \multirow{3}{*}{0.11} \\
\hline Present & $18(12.08 \%)$ & $49(8.4 \%)$ & $67(9.3 \%)$ & \\
\hline Not present & $124(87.32 \%)$ & $531(91.6 \%)$ & $655(90.7 \%)$ & \\
\hline \multicolumn{4}{|c|}{ Acanthosis Nigricans } & \multirow{3}{*}{0.02} \\
\hline Present & $8(5.6 \%)$ & $12(2.06 \%)$ & $20(2.8 \%)$ & \\
\hline Not present & $134(94.4 \%)$ & $568(97.94 \%)$ & $702(97.2 \%)$ & \\
\hline Infertility & $\operatorname{PCOS}(n=55)$ & \multicolumn{2}{|l|}{ Non-PCOS $(n=203)$} & \\
\hline Present & $12(21.8 \%)$ & $18(8.9 \%)$ & $30(11.6 \%)$ & \multirow{2}{*}{0.001} \\
\hline Not present & $43(78.2 \%)$ & $185(91.1 \%)$ & $228(88.4 \%)$ & \\
\hline
\end{tabular}

Table 5: Distribution according to family history.

\begin{tabular}{|lllll|}
\hline Family history & $\begin{array}{l}\text { PCOS }(\mathbf{n}=\mathbf{1 4 2}) \\
\text { No. of subject }(\%)\end{array}$ & $\begin{array}{l}\text { Non PCOS }(\mathbf{n}=580) \\
\text { No. of subject }(\%)\end{array}$ & $\begin{array}{l}\text { Total }(\mathbf{n}=\mathbf{7 2 2}) \\
\text { No. of subjects }(\%)\end{array}$ & p value \\
\hline Hypertension & $25(17.6 \%)$ & $100(17.2 \%)$ & $123(17 \%)$ & 0.9 \\
\hline DM & $28(19.7 \%)$ & $71(12.2 \%)$ & $99(13.7 \%)$ & 0.01 \\
\hline PCOS & $17(12 \%)$ & $37(6.4 \%)$ & $54(7.5 \%)$ & 0.02 \\
\hline
\end{tabular}

Table 6: Distribution according to BMI and WC.

\begin{tabular}{|llll|}
\hline BMI $\left(\mathrm{kg} / \mathrm{m}^{2}\right)$ & PCOS & Non PCOS & p value \\
\hline Mean \pm SD & $24.95 \pm 3.43$ & $22.26 \pm 2.76$ & 0.001 \\
\hline Waist circumference & & & \\
\hline Mean \pm SD & $80.49 \pm 11.06$ & $75.07 \pm 5.52$ & 0.001 \\
\hline
\end{tabular}

PCOS subjects mean BMI and waist circumference was higher than control group and difference between two group was statistically significant $(\mathrm{p}=0.001)$ ( Table 6).

\section{The following Table 7 shows}

- FSH levels is higher in PCOS cases than the controls. However, the difference was statistically in significant $(\mathrm{p}=0.93)$.

- $\quad$ LH levels, LH/FSH ratio and S. Testosterone levels is significantly higher in PCOS cases than controls.

Table 8 shows that

- On comparing the lipid profile, Triglyceride levels is higher in PCOS cases than controls and HDL is lower cases than controls. However, the difference between cases and control group was statistically insignificant according to lipid profile

- $\quad$ FBS $(\mathrm{mg} / \mathrm{dL})$ is higher in PCOS cases than controls. But the difference was statistically insignificant $(\mathrm{p}=$ 0.34)

- Fasting insulin levels $(\mu \mathrm{IU} / \mathrm{mL})$ and calculated HOMA-IR between two groups is significantly higher in PCOS cases than controls.

In Table 9, $88.03 \%$ were found to be positive for polycystic ovaries on ultrasonography while among non PCOS cases, $8.8 \%$ were found to be positive for polycystic ovaries on ultrasonography. It was also observed that appearance of polycystic ovaries on USG to detect PCOS has sensitivity of $88.03 \%$, specificity of $91.21 \%$, PPV of $71.02 \%$ and NPV of $96.90 \%$. 
Table 7: Distribution of according to hormonal profile.

\begin{tabular}{|lccc|}
\hline Hormonal profile & PCOS $(\mathbf{n}=\mathbf{1 4 2})$ & Non PCOS $(\mathbf{n}=\mathbf{5 8 0})$ & p value \\
\hline FSH $\mathbf{~ m I U} / \mathbf{m l}$ & & & 0.65 \\
\hline Mean \pm SD & $6.35 \pm 1.41$ & $6.29 \pm 1.52$ & 0.001 \\
\hline LH $\mathbf{~ m I U} / \mathbf{m l}$ & & & 0.001 \\
\hline Mean \pm SD & $8.704 \pm 5.53$ & $6.86 \pm 2.07$ & 0.001 \\
\hline LH/FSH & $1.35 \pm 0.79$ & $1.12 \pm 0.34$ & \\
\hline Mean \pm SD & & & \\
\hline Serum testosterones $\mathbf{n g} / \mathbf{d L}$ & $56.15 \pm 43.74$ & $36.34 \pm 22.01$ & \\
\hline Mean \pm SD & &
\end{tabular}

Table 8: Distribution according to biochemical profile.

\begin{tabular}{|c|c|c|c|}
\hline Metabolic profile & $\operatorname{PCOS}(n=142)$ & Non PCOS $(n=580)$ & p value \\
\hline \multicolumn{3}{|c|}{ Triglycerides (mg/dL) } & \multirow[b]{2}{*}{0.93} \\
\hline Mean \pm SD & $111.54 \pm 20.04$ & $109.76 \pm 21.06$ & \\
\hline \multicolumn{3}{|l|}{ HDL (mg/dL) } & \multirow{2}{*}{0.24} \\
\hline Mean \pm SD & $53.58 \pm 9.22$ & $54.44 \pm 7.48$ & \\
\hline \multicolumn{3}{|c|}{ Fasting blood sugar (mg/dL) } & \multirow{2}{*}{0.34} \\
\hline Mean \pm SD & $83.66 \pm 13.40$ & $82.58 \pm 11.81$ & \\
\hline \multicolumn{3}{|c|}{ Fasting insulin $(\mu \mathrm{IU} / \mathrm{mL})$} & \multirow{2}{*}{0.001} \\
\hline Mean \pm SD & $12.68 \pm 6.23$ & $8.50 \pm 3.88$ & \\
\hline \multicolumn{3}{|l|}{ HOMA-IR } & \multirow{2}{*}{0.001} \\
\hline Mean \pm SD & $2.67 \pm 1.57$ & $1.73 \pm 0.86$ & \\
\hline
\end{tabular}

Table 9: Distribution according to ultrasonographic findings.

\begin{tabular}{|c|c|c|c|c|}
\hline \multirow{2}{*}{ USG } & PCOS $(n=142)$ & Non PCOS $(n=580)$ & Total $(n=722)$ & p value \\
\hline & No. of subject (\%) & No. of subject (\%) & No of subject (\%) & \multirow{4}{*}{0.001} \\
\hline Polycystic ovaries & $125(88.03 \%)$ & $51(8.8 \%)$ & $176(24.4 \%)$ & \\
\hline Normal & $17(11.97 \%)$ & $529(91.2 \%)$ & $546(75.6 \%)$ & \\
\hline Total & $142(100)$ & $580(100)$ & $722(100)$ & \\
\hline
\end{tabular}

\section{DISCUSSION}

\section{Prevalence of PCOS}

PCOS is one of the most common endocrine disorders and is an emerging problem of adolescents.

To this knowledge, this is the first urban hospital-based study in this region, estimating the prevalence of PCOS among relatively younger population and its associated risk factors.

The percent prevalence of PCOS at this tertiary care teaching hospital, Jaipur, in girls aged 15-24 years was determined to be $7.5 \%, 18.68 \%, 11.18 \%$ as per the NIH, Rotterdam and AES criteria respectively. The prevalence of PCOS in this study was relatively on higher side than reported by most studies in India as tabulated below (Table 10).

The high prevalence of PCOS in this study could have been further reduced if all the enrolled girls would have participated in the study, as most of the girls who did not volunteered for study were symptom free. The variation in the prevalence of PCOS can also be likely due to different diagnostic criteria used, study settings, age group, genetic background and ethnicities.

\section{Distribution of PCOS cases according to phenotype}

In the present study, phenotype D (norm androgenic) was the most frequent $40.14 \%$, followed by phenotype A, phenotype $\mathrm{C}$ and least frequent phenotype $\mathrm{B}$.

Similar findings were reported in a study by Nidhi et al, and Joshi et al, assessing Indian adolescents, in which they reported phenotype $\mathrm{D}$ as the most prevalent phenotype and the least prevalent phenotype as phenotype $\mathrm{B}$ and $\mathrm{C} .{ }^{1,3}$ The difference in the prevalence of various phenotypes can be due to genetic, racial/ethnic and geographic variations in the study subjects. It may also depend upon the place of recruitment of study population that is from gynecology, dermatology, infertility, medicine or other department. 


\section{Distribution according to the clinical presentation}

In the present study, $80.3 \%$ PCOS presented with oligomenorrhea. The results are similar to studies conducted by Choudhary A et al, Sinha A et al, Himabindu et al, wherein significantly high percentage $68 \%, 71 \%$ and $87 \%$ of PCOS patients presented with oligomenorrhea. ${ }^{13,15,16}$

This supports to conclude that oligomenorrhea among women of reproductive age can be largely explained by PCOS.
The variation in presentation of oligoanovulation might be because OD was defined in different ways in the various studies. Further $58.9 \%$ patients of PCOS were presented with complaints of hirsutism in the present study. Again, the percentage is comparable to studies conducted by Anjali $\mathrm{C}$ et al, Sinha A et al, Himabindu et al, Lakshmi KS et al and Sunita $\mathbf{J}$ et al. ${ }^{13,15-18}$ Who observed that $64.2 \%, 21 \%, 48 \%, 47.8 \%$ and $44.16 \%$ patients of PCOS presented with complaints of hirsutism respectively. As this study's being hospital based could be the possible explanation for the high prevalence of hirsutism observed.

Table 10: The prevalence of PCOS in this and other studies.

\begin{tabular}{|c|c|c|c|c|}
\hline Source & Year & Population & State & Prevalence of PCOS \\
\hline Present study & 2017-2019 & $722(15-24$ years $)$ & Jaipur & $\begin{array}{l}7.5 \% \text { (NIH) } \\
18.68 \% \text { (Rot) } \\
11.18 \% \text { (AES) }\end{array}$ \\
\hline Upadhya RSS et al $^{12}$ & 2018 & 246 (17-26years) & Tamil Nadu & $32.11 \%$ \\
\hline Singh A et $\mathrm{al}^{13}$ & 2017-2018 & 117 (15-19 years) & Hyderabad & $11.96 \%$ \\
\hline Desai NA et a ${ }^{14}$ & 2014-2015 & 881 (13-18 years) & Ahmedabad & $13.54 \%$ \\
\hline Joshi B et al ${ }^{1}$ & 2010-2011 & 600 (15-24 years) & Mumbai & $22.5 \%$ \\
\hline Nidhi $R$ et $\mathrm{al}^{3}$ & 2010-2011 & 460(15-18year) & Andhra Pradesh & $9.13 \%$ \\
\hline
\end{tabular}

Hyperandrogenism commonly manifests itself as hirsutism and acne. Authors observed that $12.9 \%$ PCOS women presented with complaints of acne which was comparable to studies done by Himabindu et al and Sunita $\mathbf{J}$ et al, where $12 \%$ and $20 \%$ of the PCOS cases had acne. ${ }^{16,18}$

PCOS patients are at a great risk of infertility and is one of the long-term sequelae of PCOS.

Study found that among 55 married women $21.8 \%$ of women complained of infertility. However, Choudhary A et al, Himabindu et al, and Sunita $\mathrm{J}$ et al observed higher percentage of infertility in PCOS patients which was $40 \%, 40 \%$ and $44.68 \%$ respectively. ${ }^{15,16,18}$ Low prevalence of infertility as observed in this study when compared to other studies could be because of lesser age group of subjects involved in the study.

Study observed signs of hyperinsulinism in $5.6 \%$ of PCOS and $2.06 \%$ of non PCOS cases which was lower than most of the other studies reported. The reason of this could be that to younger age group and overall a smaller number of obese subjects covered in this study.

On further comparing these symptoms between PCOS and non PCOS group it was observed that, the prevalence of menstrual irregularity, hirsutism, infertility and acanthosis nigricans was found significantly higher in PCOS girls as compared to non PCOS girls and there was found to be statistically significant correlation between these symptoms and PCOS $(\mathrm{p}<0.5)$.

\section{Distribution according to family history}

Study observed that the higher number of study participants had a positive family history of PCOS and DM in PCOS group than non-PCOS group.

Saidunnisa $G$ et al observed that the participants with family history of PCOS carry more for development of PCOS Desai NA et al observed that statistically significant PCOS girls $(37.81 \%)$ had family history of $\mathrm{DM}$ as compared to normal girls. ${ }^{14,19}$ Authors can conclude that there is genetic predisposition for PCOS which leads to increased risk of PCOS among first-degree relatives of PCOS and diabetic patients.

\section{Distribution according to BMI and WC}

Authors observed that, in this study PCOS patients had a mean BMI of $24.87 \pm 3.45\left(\mathrm{~kg} / \mathrm{m}^{2}\right)$ and waist circumference $(\mathrm{cm})$ of $80.49 \pm 11.06 \mathrm{~cm}$ while the control subjects had mean BMI of $22.26 \pm 2.76$ and waist circumference of 75.07 \pm 5.52 . Thus, denoting a significant correlation between obesity and PCOS.

Kumarapeli $\mathrm{V}$ et al demonstrated similar result where BMI (24.2) and WC $(84 \mathrm{~cm})$ were significantly greater 
among women with PCOS than among age-matched definite controls (BMI-21.8 and WC- 77). ${ }^{20}$

\section{Distribution of according to hormonal profile}

Hashemi AH et al found the mean LH levels of cases was significantly higher than control $(8.3 \pm 7.1$ and $5.4 \pm 1.3$, p $=0.004$ ) while the FSH levels of cases were higher than control but not statistically significant $(7.1 \pm 3.7$ and $6.4 \pm 1.95, \mathrm{p}=0.5)^{21}$

Gupta V et al, also observed similar results where mean LH levels of cases was significantly higher than control while the FSH levels of cases were higher than control but not statistically significant. ${ }^{22}$

This findings were consistent and comparable with above studies and thus along with the aforementioned studies authors conclude that most women with PCOS have elevated $\mathrm{LH}$ and $\mathrm{LH} / \mathrm{FSH}$ ratio.

Similar results were reported in various studies by Kumarapeli $\mathrm{V}$ et al, Maheswari et al and Simun $\mathrm{M}$ et al they observed that total testosterone level was significantly greater among women with PCOS when compared with age matched controls. ${ }^{20,23,24}$ This difference in two group was highly significant statistically $(\mathrm{p}=0.001)$.

Increased Hormonal profile like LH, LH/FSH ratio and testosterone leads to disturbances in the interlinked hormonal and biochemical pathways contributing to PCOS and are considered significant risk factors for developing PCOS.

\section{Distribution according to biochemical profile}

\section{Lipid profile}

Dyslipidemia is considered to be a common metabolic derangement in PCOS. We, therefore, compared lipid profile in PCOS and non PCOS women Amini L et al, reported similar result as this study, they concluded that mean TG levels is higher in PCOS group $(135.03 \pm 151.40)$ as compared to non PCOS group $(116.55 \pm 45.81)$ but this difference was not statistically significant $(\mathrm{p}=0.44) .{ }^{25}$ On comparing HDL levels they concluded that mean HDL levels in PCOS is slightly more $(56.81 \pm 25.91)$ when compared with non PCOS group $(55.34 \pm 18.02)$ but this difference between them is also statistically insignificant $(\mathrm{p}=0.77)$. Joshi et al also found no statistically significant difference in lipid profile of adolescents $(\mathrm{p}>0.05){ }^{1}$

\section{Insulin resistance indices}

In this study mean FBS had no significant association with controls. This finding was consistent to the finding of various studies Vipul et al, reported that the mean FBS levels in PCOS was near normal 79.92 $\pm 8.55 \mathrm{mg} \%$, while in control group, it was $77.50 \pm 7.78 \mathrm{mg} \%$ but the mean difference was statistically insignificant $(\mathrm{p}=0.261){ }^{22}$

Joshi et al and Alebic MS also reported that the mean FBS level of PCOS cases were near normal and was not different statistically from non PCOS adolescent girls. ${ }^{1,24}$

Study observed that the serum fasting Insulin level is higher in PCOS Cases than Controls and the difference was statistically significant $(\mathrm{p}=0.001)$.

The findings of this study was similar to other studies like Joshi et al, Alebic MS et al, Thangavelu et al, Fruzzetti F et al which reported that mean serum fasting insulin levels were significantly higher in PCOS when compared with that of control. ${ }^{1,23,24,26}$

The HOMA-IR levels was also significantly higher in PCOS group and the findings of this study was similar to other studies Thangavelu M, Simun M and Fruzzetti F, which also reported that mean HOMA-IR levels were higher in PCOS when compared with that of non PCOS group. ${ }^{23,24,26}$

Study along with the above-mentioned various studies found that PCOS women had significantly higher insulin concentrations and HOMA-IR value indicating decreased insulin sensitivity in PCOS and, thus, a higher risk for developing IR-associated metabolic disorders such as impaired glucose tolerance, type 2 diabetes, the metabolic syndrome and potentially cardiovascular disease.

However, no difference was found in concentration of fasting glucose between PCOS and controls supporting that fasting glucose could not serve as a sensitive indicator of IR in PCOS women.

\section{Distribution according to ultrasonographic findings}

USG appearance of ovaries though is a diagnostic criterion according to Rotterdam criteria, all women may not have typical polycystic ovaries.

In this observation, $88.03 \%$ PCOS women had Ultrasonographic appearance of polycystic ovaries. This result was consistent with Seddigheh et al and Kumarapeli V, who claimed $89.1 \%$ and $96.7 \%$ PCOS cases showed PCOS in USG respectively. ${ }^{20,27}$

The study found the sensitivity and specificity of Ultrasonographic appearance of polycystic ovaries in this study as 88.03 and $91.2 \%$ and the PPV and NPV as $71.02 \%$ and $96.9 \%$.

\section{CONCLUSION}

The percent prevalence of PCOS at the tertiary care teaching hospital in Jaipur in adolescent and young girls aged 15-24 years has been determined to be $7.5 \%$, 
$18.68 \%$ and $11.18 \%$ as per NIH, Rotterdam and AES criteria respectively.

From this study it was clear that PCOS is a common disorder among young women and the incidence of PCOS among adolescence has seen an increasing trend.

The study concluded that the factors which have shown statistically significant association with presence of PCOS include $\mathrm{BMI}>30$, waist circumference $>80 \mathrm{~cm}$, hyperandrogenic manifestations, menstrual irregularity (oligomenorrhea) and family history of PCOS and DM. The risk of PCOS increases with presence of one or more of these identified predisposing factors. Most of these factors tested as predisposing factors in this study are interlinked to each other and are mostly modifiable.

PCOS women have a hormonal imbalance and metabolism problems that can affect their health and fertility. There was a statistically significant association of Serum LH, LH/FSH ratio, S. Testosterones, Serum insulin and HOMA-IR with PCOS.

The study also observed that deranged lipid profile was not significantly associated with PCOS. No significant difference was found in FBS levels between PCOS and non PCOS group and hence serum Insulin and HOMA-IR levels were more significant and sensitive indicator of Insulin resistance. Therefore, use of these simple hormonal and metabolic parameters might help in early screening and detection of the metabolic changes and help to identify women with PCOS and its long-term sequel.

Awareness creation in general population regarding this disease and associated complication is required which should be followed with proper counselling regarding importance of early diagnosis so that one can inculcate early life style modifications and prevent metabolic and reproductive complications of this disease.

Lifestyle modifications for weight reduction and dietary modifications and psychological counselling plays important role in these young girls for preventing long term future complications.

Funding: No funding sources

Conflict of interest: None declared

Ethical approval: The study was approved by the Institutional Ethics Committee

\section{REFERENCES}

1. Joshi B, Mukherjee S, Patil A, Purandare A, Chauhan S, Vaidya R. A cross-sectional study of polycystic ovarian syndrome among adolescent and young girls in Mumbai, India. Indian J Endocrinol Metabol. 2014;18(3):317-24.

2. Radha P, Devi RS, Madhavi J. Comparative study of prevalence of polycystic ovarian syndrome in rural and urban population. J Adv Med Dent Sci Res. 2016;4(2):90.

3. Nidhi R, Padmalata V. Prevalence of polycystic ovarian syndrome in Indian adolescents. J Paediatr Adolescents Gynecol. 2011;24(4):223-7.

4. Gill H, Tiwari P, Dabadghao P. Prevalence of polycystic ovary syndrome in young women from North India: a community-based study. Indian J Endocrinol Metabol. 2012;16 (Suppl 2):S389-S392.

5. Toulis KA, Goulis DG, Kolibianakis EM, Venetis CA, Tarlatzis BC, Papadimas I. Risk of gestational diabetes mellitus in women with polycystic ovary syndrome: a systematic review and a meta-analysis. Fertil Steril. 2009;92(2):667-77.

6. Malik S, Jain K, Talwar P, Prasad S, Dhorepatil B, Devi G, et al. Management of polycystic ovary syndrome in India. Fertil Sci Res. 2014;1:23-43.

7. Patil M. Pathophysiology of PCOS. The PCOS Society of India Newsletter. PANDORA. 2016;1:68.

8. Azziz R, Marin C, Hoq L, Badamgarav E, Song P. Health care-related economic burden of the polycystic ovary syndrome during the reproductive life span. J Clin Endocrinol Metab. 2005;90:4650-8.

9. Zawadski JK, Dunaif A. Diagnostic criteria for polycystic ovary syndrome: towards a rational approach. In: Dunaif A, Givens JR, Haseltine FP, Merriam GR, eds. Polycystic Ovary Syndrome. Boston: Blackwell Scientific Publications; 1992:377384.

10. Rotterdam ESHRE/ASRM-Sponsored PCOS Consensus Workshop Group. Revised 2003 consensus on diagnostic criteria and long-term health risks related to polycystic ovary syndrome. Fertil Steril. 2004;81:19-25.

11. Azziz R, Carmina E, Dewailly D, DiamantiKandarakis E, Escobar-Morreale HF, Futterweit W, et al. Androgen excess society. Position statement: criteria for defining PCOS as a predominantly hyperandrogenic syndrome: An Androgen Excess Society guideline. J Clin Endocrinol Metab. 2006;91:4237-45.

12. Upadhya RS, Tripathy S, Mohapatra S. Prevalence of poly cystic ovarian syndrome among students of a tertiary care teaching hospital. Indian $\mathbf{J}$ Obstet Gynecol Res. 2018;5(4):481-4.

13. Singh A, Vijaya K, Laxmi KS. Prevalence of polycystic ovarian syndrome among adolescent girls: a prospective study. Int $\mathbf{J}$ Reprod Contracept Obstet Gynecol. 2018;7:4375-8.

14. Desai NA, Tiwari RY, Patel SS. Prevalence of polycystic ovary syndrome and its associated risk factors among adolescent and young girls in Ahmedabad Region. Indian J Pharma Pract. 2018;11(3):119.

15. Choudhary A, Jain S, Chaudhari P. Prevalence and symptomatology of polycystic ovarian syndrome in Indian women: is there a rising incidence. Inter $\mathrm{J}$ Reprod Contra Obstet Gynecol. 2017;6(11):4971-5. 
16. Sangabathula H, Varaganti N. Clinical profile polycystic ovarian syndrome - 100 cases. Int J Conte Med Res. 2017;4(6):1249-53.

17. Laxmi - Lakshmi KS, Jayasutha J, Chandrasekar A. A study on prevalence of polycystic ovary syndrome at a tertiary care hospital. Int $\mathrm{J}$ Pharm Sci Res. 2015;6(1):383-5.

18. Sunita J, Ramanand SJ, Ghongane BB, Ramanand JB, Patwardhan MH, Ghanghas RR, et al. Clinical characteristics of polycystic ovary syndrome in Indian women. Indian J Endocr Metab. 2013;17:13845 .

19. Begum GS, Shariff A, Ayman G, Mohammad B, Housam R, Khaled N. Assessment of risk factors for development of polycystic ovarian syndrome. Int $\mathbf{J}$ Conte Med Res. 2017;4(1):164-7.

20. Kumarapeli V, Seneviratne RD, Wijeyaratne CN, Yapa RM, Dodampahala SH. A simple screening approach for assessing community prevalence and phenotype of polycystic ovary syndrome in a semiurban population in Sri Lanka. Am $\mathbf{J}$ Epidemiol. 2008;168:321-8.

21. Hashemi AH, Mozdarani H, Naghavi A. Comparison of the Levels of LH and FSH, TSH, Prolactin, progesterone and estradiol hormones between Iranian infertile women with polycystic ovary syndrome and healthy women. Int $\mathbf{J}$ Med Res Health Sci. 2016;5(12):370-5.

22. Gupta V, Sharma S, Raina SK, Bedi GK. Clinical, ultrasonographic, and biochemical correlates of polycystic ovarian syndrome: a case-control study from a tertiary care center in North India. J Sci Soc. 2018;45:8-12.
23. Thangavelu M, Godla UR, Godi S, Paul SF, Maddaly R. A case-controlled comparative hospitalbased study on the clinical, biochemical, hormonal, and gynecological parameters in polycystic ovary syndrome. Indian J Pharm Sci. 2017;79(4):608-16.

24. Alebić MŠ, Bulum T, Stojanović N, Duvnjak L. Definition of insulin resistance using the homeostasis model assessment (HOMA-IR) in IVF patients diagnosed with polycystic ovary syndrome (PCOS) according to the Rotterdam criteria. Endocrine. 2014;47(2):625-30.

25. Amini L, Sadeghi MR, Oskuie F, Kamali K, Maleki H. Lipid profile in women with polycystic ovary syndrome. Crescent J Med Biol Sci. 2014;1(4):14750.

26. Fruzzetti F, Perini D, Lazzarini V, Parrini D, Genazzani AR. Adolescent girls with polycystic ovary syndrome showing different phenotypes have a different metabolic profile associated with increasing androgen levels. Fertil Steril. 2009;92(2):626-34.

27. Esmaeilzadeh S, Andarieh MG, Ghadimi R, Delavar MA. Body mass index and gonadotropin hormones (LH and FSH) associate with clinical symptoms among women with polycystic ovary syndrome. Global J Health Sci. 2015;7(2):101.

Cite this article as: Jain A, Garg S, Sharma U. Polycystic ovarian syndrome among adolescent and young women: a hospital based observational study in a tertiary care teaching Hospital. Int J Reprod Contracept Obstet Gynecol 2020;9:1097-105. 